\title{
LINKAGE OF LOOP-TAIL, LEADEN, SPLOTCH AND FUZZY IN THE MOUSE
}

\author{
GEORGE D. SNELL," MARGARET M. DICKIE, PRISCILLA SMITH and \\ DIANE E. KELTON
}

Roscoe B. Jackson Memorial Laboratory, Bar Harbor, Maine

Investigations by Dickie and Woolley (1950) and Fisher (1953) have established a linkage group (number thirteen) in the mouse carrying the genes leaden (ln), fuzzy ( $f z)$, polydactyly ( $p y)$, and probably Splotch $(S p)$. The published crossover values are : $\ln -f z, 40 \cdot 9 \pm 3 \cdot 7$ per cent. where the heterozygous parent is the female and $4 \mathrm{I} \cdot 5 \pm$. 4.5 per cent. where the heterozygous parent is the male (Dickie and Woolley, r95o) ; $f z-S p, 4$ r $3 \pm 5 \cdot 2$ per cent. (Dickie and Woolley, 1950) ; ln $-p y, 40 \cdot 3 \pm \mathrm{r} \cdot 77$ per cent. where the heterozvgous parent is the female and $23^{\circ} 0 \pm 2 \cdot 00$ per cent. where the heterozygous parent is the male (Fisher, 1953). No three-point or four-point data have been reported.

Table I shows the results from two sets of crosses, one involving $l n, S p$ and $f z$ and the other $L p$ (Loop-tail : Strong and Hollander, r949; Stein and Rudin, I953), ln and $f z$. It will be seen that the data establish the linkage of these four genes with the order and crossover per cents. as follows :

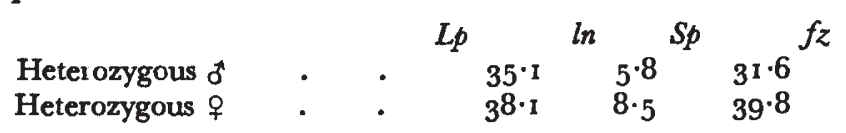

While these were the two most important crosses, two others gave results which deserve mention.

The leaden Splotch linkage was first discovered by Mrs Ann Ingalls (data previously unpublished) in a backcross of $S p$ to the V stock, a multiple-factor stock carrying $a, \ln , s, v, w a+1$. The segregation of piebald $(s)$ in this cross complicated the classification of $S p$. However, a frequency distribution of the animals classified according to the total area of white spotting gave an indication of four modes which presumably corresponded to the four classes $s p s p S s, S p s p S s$, spspss and Spspss. There was more overlapping between the SpspSs and the spspss classes than between these and the two extreme classes. The class with maximum white included animals with up to go per cent. of the coat unpigmented, considerably more than is ever seen in the $\mathrm{V}$ stock due to piebald alone. Evidently the effect of $S p$ and $s$ in combination is more than additive. The selection of lines to divide the four classes was necessarily somewhat arbitrary; the lines finally

* Currently Guggenheim Fellow at the Department of Zoology, University of Texas, Austin, Texas. 


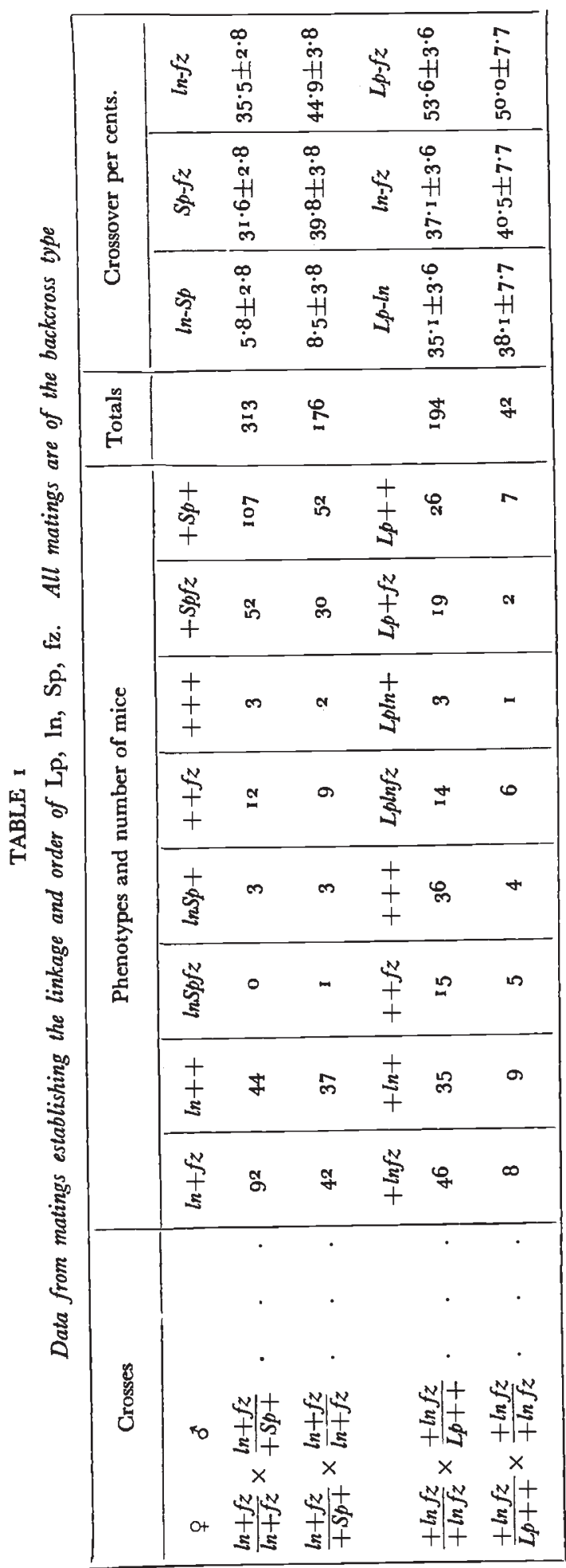


selected yielded a figure for crossing over between $\ln$ and $S p$ of $9 \cdot 7 \pm$ 4.5 per cent. in heterozygous males, and $9.8 \pm 7.8$ per cent. in heterozygous females.

Data indicating an apparent linkage of $S p$ and $S d$ were reported in a previous publication (Dickie, Kelton et al., 1949). Since $S d$ was subsequently shown to belong in linkage group five (Wallace, 1950), some explanation of this case is necessary. The data came from matings of a single heterozygous male, with $S p$ and $S d$ in repulsion, to $\mathrm{C}_{57} \mathrm{BL}$ females. Final tabulation, including published and previously unpublished data, gave results as follows :

$$
\begin{array}{cccc}
++ & S p+ & +S d & S p S d \\
3^{8} & 64 & 39 & 29
\end{array}
$$

It will be seen that the apparent linkage is due to the excess of animals in the $S p+$ class. Only additional tests, not now contemplated, could establish definitely the reason for this unequal distribution. One possible explanation is a second spotting factor actually closely linked with $S d$, which mimics $S p$ in phenotype and has, as $S p$ sometimes does, incomplete penetrance. $S p$ and the postulated gene are assumed to have entered the cross from one parent, $S d$ from the other.

Acknowledgments.-This investigation has been aided by a research grant $\mathrm{C}_{-1}{ }^{2} 29$ from the National Cancer Institute, of the National Institutes of Health, Public Health Service, Department of Health, Education, and Welfare.

We are indebted to $\mathrm{Dr}$ L. C. Strong and Mr Willard Hollander for providing us with the Loop-tail mice. Mr Hollander also sent information that he had found no evidence of linkage between Loop-tail and albino, pink-eye, short-ear, piebald, nonagouti or brown.

\section{REFERENCES}

DICKIE, MARGARET M., KELTON, DIANE E., FIELDER, JUDiTH H., INGALls, ANN M., AND SNELL, G. D. 1949. New mutations and linkage studies in the house mouse (Mus musculus). Anat. Record, ro5, 540.

Dickie, Margaret M., AND WOolley, G. w. 1950. Fuzzy mice. F. Hered., $4^{I}$, 193-196.

FISHER, R. A. 1953. The linkage of polydactyly with leaden in the house-mouse. Heredity, 7, $91-95$.

STEIN, X. F., AND RUDIN, IRIS A. 1953. Development of mice homozygous for the gene for looptail. F. Hered., 44, 59-68.

STRONG, L. C., AND HOLLANDER, W. F. 1949. Hereditary Loop-tail in the house mouse. J. Hered., 40, 329-334.

WALLACE, M. E. 1950. Locus of the gene "fidget" in the house mouse. Nature (Lond.), 166,407 . 